\title{
Application of Modified Magnetite Nanoparticles as a New Sorbent for Separation/Preconcentration of Mercury(II) Trace Amounts and its Determination by Cold Vapor Atomic Absorption Spectrometry
}

\author{
Mohammad Ali Karimi, ${ }^{\text {a,b,* }}$ Abdolhamid Hatefi-Mehrjardi, ${ }^{a, b}$ and Asghar Askarpour Kabir ${ }^{b}$ \\ a Department of Chemistry, Payame Noor University, 19395-4697, Tehran, Iran \\ ${ }^{\mathrm{b}}$ Department of Chemistry \& Nanoscience and Nanotechnology Research Laboratory (NNRL), \\ Payame Noor University, Sirjan, Iran
}

RECEIVED SEPTEMBER 28, 2012; REVISED MARCH 12, 2014; ACCEPTED MARCH 18, 2014

\begin{abstract}
A new, simple, fast and reliable method has been developed to separation/preconcentration of trace amounts of mercury ions using dithizone/sodium dodecyl sulfate-immobilized on alumina-coated magnetite nanoparticles (DTZ/SDS-ACMNPs) and its determination by cold vapor atomic absorption spectrometry (CVAAS). This method avoided the time-consuming column-passing process of loading large volume samples in traditional solid phase extraction (SPE) through the rapid isolation of DTZ/SDSACMNPs with an adscititious magnet. Under the optimal experimental conditions, the enrichment factor, detection limit, linear range and relative standard deviation (RSD) of $\mathrm{Hg}(\mathrm{II})$ ions were 250 (for $500 \mathrm{~mL}$ of sample solution), $0.058 \mu \mathrm{g} \mathrm{mL} L^{-1}, 0.2-80.0 \mu \mathrm{g} \mathrm{mL}^{-1}$ and $3.55 \%$ (for $5.0 \mu \mathrm{g} \mathrm{mL} \mathrm{g}^{-1}, n=10$ ), respectively. The adsorbed mercury ions were quantitatively eluted by $2.0 \mathrm{~mL}$ of $0.4 \mathrm{~mol} \mathrm{~L}^{-1} \mathrm{HBr}$ solution. The presented procedure was successfully applied for determination of mercury content in the different samples of water and blood.
\end{abstract}

Keywords: Solid-phase extraction, alumina-coated magnetite nanoparticles, mercury(II), dithizone, cold vapor-atomic absorption spectrometry

\section{INTRODUCTION}

In recent years, there has been an increased concern over the concentration of mercury in drinking and natural water due to its high toxicity and pollution to the environment, and especially the aquatic system. ${ }^{1,2}$ Mercury is leached from rocks and soil into water system by natural processes, some of which are accelerated by human activities.

There are several analytical techniques for mercury determination at sub-ppb levels such as electroanalyt$\mathrm{ical}^{3}{ }^{3}$ inductively coupled plasma-atomic emission spectrometry (ICP-AES), ${ }^{4}$ inductively coupled plasma-mass spectrometry (ICP-MS), ${ }^{5,6}$ atomic fluorescence spectrometry ${ }^{7}$ and neutron activation analysis. ${ }^{8}$ Cold vaporatomic absorption spectrometry (CV-AAS) is a very efficient, simple, low cost and widely used technique for accurate determination of sub-micrograms per milliliters of mercury. ${ }^{9-11}$ However, due to its low concentrations in numerous samples and high levels of non-toxic components that usually accompany analytes (especially marine samples), a cleanup and preconcentration step is often necessary prior to its measurement. ${ }^{12}$
The direct determination of trace metals especially toxic metal ions such as mercury, from various samples requires mostly an initial and efficient preconcentration step. ${ }^{13}$ This preconcentration is required to meet the detection limits as well as to determine the lower concentration levels of the analyte of interest. ${ }^{14}$ This can be performed simply in many ways including liquid and solid phase extraction (SPE) techniques. ${ }^{15,16}$ The application of SPE technique for preconcentration of trace metals from different samples results in several advantages such as the minimal waste generation, reduction of sample matrix effects as well as sorption of the target species on the solid surface in a more stable chemical form. ${ }^{17}$ An efficient SPE method should consist of a stable and insoluble porous matrix having suitable active groups (typically organic groups) that interact with heavy metal ions. ${ }^{18}$ So far, numerous substances have been applied for preconcentration of mercury, such as dithiocarbamate derivatives, ${ }^{19-21}$ cysteine, ${ }^{22} 4-$ (2-pyridylazo)-resorcinol, ${ }^{23}$ dithioacetal derivatives, ${ }^{24,25}$ aliphatic amines 2-thiophenecarboxaldehyde, ${ }^{26}$ etc. However, the main problems associated with these materials

\footnotetext{
* Author to whom correspondence should be addressed. (E-mail: ma.karimi43@gmail.com,m_karimi@pnu.ac.ir)
} 
are time consuming and high cost for their preparation and operating difficulties. Exploring new functional materials are still necessary because of complexities of real samples and analysis demand.

At present, nanometer material has become more and more important due to its special properties. Although investigations of the surface chemistry of highly dispersed oxides, e.g. $\mathrm{TiO}_{2}, \mathrm{Al}_{2} \mathrm{O}_{3}, \mathrm{ZrO}_{2}, \mathrm{SiO}_{2}$ and $\mathrm{ZnO}$, indicated that these materials had very high adsorption capacity, ${ }^{27-31}$ but separation of these particles from aqueous medium is difficult because of very small dimension and high dispersion. In this study, a new method combining nanoparticles adsorption with magnetic separation has been developed and applied for the separation and preconcentration of mercury ions. ${ }^{32-35}$ Magnetite nanoparticles have been successfully applied to separate some proteins and organic compounds ${ }^{36,37}$ and some heavy metal ions. ${ }^{38-43}$ These methods were based on the solid-phase extraction of trace amounts of silver and lead ions using dithizone/sodium dodecyl sulfateimmobilized on alumina-coated magnetite nanoparticles. ${ }^{44,45}$ Surfactant molecules are known to form selfaggregates called "hemimicelles" or "admicelles" on solid alumina surfaces in acidic medium. Insoluble hydrophobic compounds can be solubilized in hydrocarbon cores of these micelles. In this work, sodium dodecyl sulfate (SDS) immobilized on alumina-coated magnetite nanoparticles was used for the collection of insoluble as a Chelating agent for preconcentration of $\mathrm{Hg}$ ions in water samples. ${ }^{46}$

In this study, a new method combining nanoparticles adsorption with magnetic separation has been developed and applied for the separation and preconcentration of mercury ions. Dithizone (DTZ) was chosen as doping reagent because of its favorable coordination capacity and selectivity for $\mathrm{Hg}$ (II). It is concluded from the extraction data that the new sorbent is a promising material for the SPE of mercury. In this paper, we will explore the possibility of dithizone/sodium dodecyl sulfate immobilized on alumina-coated magnetite nanoparticles (DTZ/SDS-ACMNPs) to act as SPE sorbents for the separation/ preconcentration of trace level of mercury ions from environmental samples prior to determination by $\mathrm{CV}$-AAS technique.

\section{EXPERIMENTAL}

\section{Apparatus}

A flame atomic absorption spectrophotometer (PG Instruments, model PG 990, England) equipped with a mercury hollow cathode lamp as light source and hydride vapor generator (WHG-103 A) was used for mercury generation and absorbance measurements, The mercury compounds were reduced to metallic mercury
Table 1. Applied conditions for mercury determination with the WHG-103 A (CV) system

\begin{tabular}{|c|c|}
\hline Parameter & Applied conditions \\
\hline Measurement mode & Continuous-flow method \\
\hline Signal processing & Integrated hold \\
\hline Integration time / s & 10 \\
\hline Argon carrier gas flow rate ${ }^{(a)}$ & 80 \\
\hline Sample aspiration flow rate ${ }^{(a)}$ & 4.5 \\
\hline $5.0 \mathrm{~mol} \mathrm{~L}^{-1} \mathrm{HCl}$ flow rate ${ }^{(\mathrm{a})}$ & 2.1 \\
\hline $0.5 \% \mathrm{NaBH} 4$ flow rate ${ }^{(\mathrm{a})}$ & 2.0 \\
\hline
\end{tabular}

${ }^{(a)}$ Expressed in $\mathrm{mL} \mathrm{min}^{-1}$.

with sodium tetrahydroborate and the mercury generator was operated with argon as carrier gas. All the measurements were carried out in the cold state under the conditions given in Table 1. A Fourier transform infrared spectrometer (FTIR Prestige-21, Shimadzu), scanning electron microscope (LEO 1455VP SEM) and vibrating sample magnetometer (VSM 7400 Model Lake-Shore) were used to characterize the structure of the prepared MNPs and DTZ/SDS-ACMNPs. The pH measurements were conducted by a Metrohm $780 \mathrm{pH}$ meter calibrated against two standard buffer solutions of $\mathrm{pH}=4.0$ and 9.0. Other instruments used were: mechanical stirrer (Heidolph, RZR2020), ultrasonic bath (S60H Elmasonic, Germany) and orbital shaker (Ika, KS130 Basic). In addition, for magnetic separations a strong neodymium-iron-boron $\left(\mathrm{Nd}_{2} \mathrm{Fe}_{12} \mathrm{~B}\right)$ magnet $(1.2 \mathrm{~T}$, $2.5 \times 5 \times 10 \mathrm{~cm}$ ) was used.

\section{Reagents and Solutions}

All of the chemicals were of analytical grade and all solutions were prepared by double distilled de-ionized water with electric conductivity below $1.2 \mu \mathrm{S} \mathrm{cm} \mathrm{cm}^{-1}$. All of the chemicals were obtained from Merck (Darmstadt, Germany). A stock $1000 \mathrm{mg} \mathrm{mL}^{-1}$ of mercury (II) was prepared by dissolving $0.1354 \mathrm{~g}$ of $\mathrm{HgCl}_{2}$ in $5 \mathrm{~mL}$ of concentrate nitric acid and was diluted to $100 \mathrm{~mL}$. The $\mathrm{pHs}$ of the solutions were adjusted with phosphate buffer. ferrous chloride $\left(\mathrm{FeCl}_{2} \cdot 4 \mathrm{H}_{2} \mathrm{O}\right)$, ferric chloride $\left(\mathrm{FeCl}_{3} \cdot 6 \mathrm{H}_{2} \mathrm{O}\right)$, 1,5-diphenyl carbazone (DTZ), sodium dodecylsulfate (SDS), aluminum isopropoxide, ethanol, hydrobromic acid, ammonia, hydrochloric acid and sodium hydroxide were used without further purification processes.

\section{Preparation of Alumina-coated Magnetite Nanoparticles (ACMNPs)}

The $\mathrm{Fe}_{3} \mathrm{O}_{4}$ nanoparticles (MNPs) and alumina-coated magnetite nanoparticles (ACMNPs) were prepared by chemical coprecipitation methods as reported in our previous works. ${ }^{44,45}$ At first step the MNPs were 

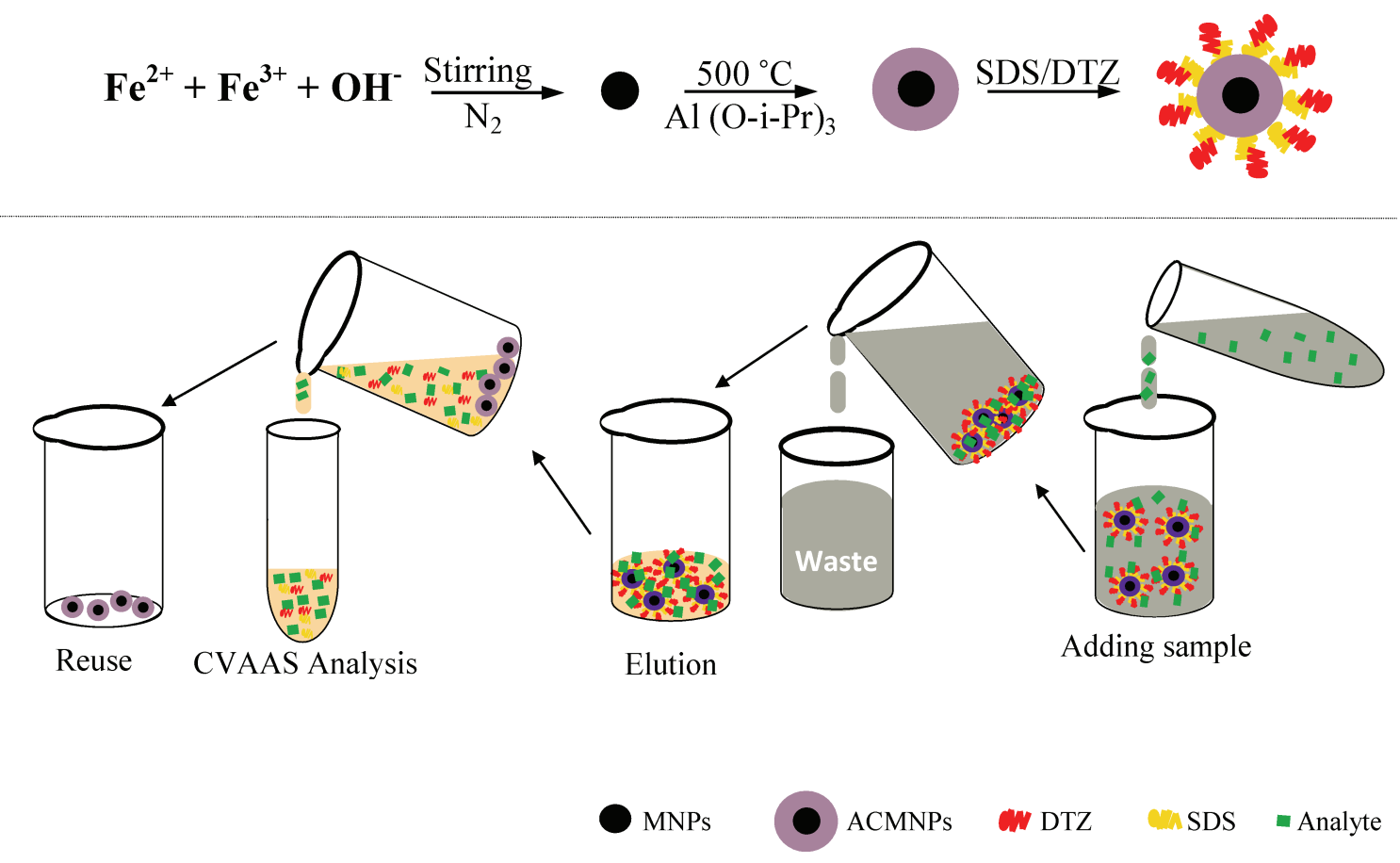

Figure 1. Procedure for magnetic solid-phase extraction.

prepared by chemical co-precipitation procedure. After the reaction, the obtained MNPs precipitate was separated from the reaction medium under the magnetic field, and rinsed with $200 \mathrm{~mL}$ pure deionized water four times. Then, the product was oven dried at $80^{\circ} \mathrm{C}$.

At the next step for preparation of ACMNPs, aluminum isopropoxide $(1.0 \mathrm{~g})$ was dissolved in ethanol $(60 \mathrm{~mL})$ to form a clear solution. MNPs $(0.1 \mathrm{~g})$ were then dispersed in the freshly prepared solution for $5 \mathrm{~min}$ with the aid of ultrasonic waves. A mixture of water and ethanol (volume ratio: 1:5) was added dropwise to the suspension of MNPs with vigorous stirring. The mixture was stirred for half an hour after the addition. Subsequently, the suspension was standing for one hour before separating and washing with ethanol. After five cycles of separation/washing/redispersion with ethanol, the powder obtained was oven dried and calcined at $500{ }^{\circ} \mathrm{C}$ for three hours.

\section{General Procedure}

The procedure for the magnetic extraction (MSPE) consists of three steps: firstly, $10 \mathrm{~mL}$ of DTZ/SDS solution $\left(0.1 / 0.02 \mathrm{mmol} \mathrm{L}^{-1}\right)$ was added to $0.05 \mathrm{~g}$ ACMNPs and the $\mathrm{pH}$ was adjusted to about 2.0 by dropwise addition of $0.1 \mathrm{~mol} \mathrm{~L}^{-1} \mathrm{HNO}_{3}$ solution, the mixture was shaken and for $2 \mathrm{~min}$. Furthermore, the magnet was deposited at the bottom of the beaker and the DTZ/SDS coated ACMNPs were isolated from their suspension. Secondly, $10 \mathrm{~mL}$ of $\mathrm{Hg}(\mathrm{II})$ ion solution $\left(10 \mu \mathrm{g} \mathrm{mL}^{-1}\right)$ was transferred to this sorbent and the $\mathrm{pH}$ value was adjusted to $\sim 3.5$ with phosphate buffer and, the soluti- on was shaken for $5 \mathrm{~min}$ to facilitate adsorption of the metal ions onto the nanoparticles; and finally, the magnetic adsorbent was separated using magnet and the adsorbed ions were eluted with $2 \mathrm{~mL} \mathrm{HBr}$ solution $0.4 \mathrm{~mol} \mathrm{~L}^{-1}$. And this eluate solution was also separated for CV-AAS analysis. Illustration of the whole procedure of the preparation of ACMNPs and its application as MSPE sorbents for enriching analyte can be followed in Figure 1.

\section{Sample Preparation Procedure for Water}

Water samples (i.e., tap water, river and spring water), were filtered through filter paper (Whatman, No. 4) to remove suspended particulate matter after collection and acidified to a $\mathrm{pH}$ of about 1.0 with concentrated $\mathrm{HNO}_{3}$ prior to storage in polyethylene container for use. Subsequently were neutralized with concentrated $\mathrm{NH}_{3}$ and then $\mathrm{pH}$ of solutions were adjusted to 3.0. The SPE procedure was carried out as described in general procedure

\section{Sample preparation procedure for blood}

Five samples of blood were obtained from healthy human bodies by in the sterile blood collecting tubes containing EDTA as anticoagulant. $4 \mathrm{~mL}$ conc. $\mathrm{HNO}_{3}$ was added to $5 \mathrm{~mL}$ from each samples and heated for 15 minutes at $80^{\circ} \mathrm{C}$, and then $2 \mathrm{~mL} \mathrm{H}_{2} \mathrm{O}_{2}$ was added and heated for 20 minutes again. After filtering and eluting with $10 \mathrm{~mL}$ diluted nitric acid, the resultant solution was neutralized and diluted. Then $\mathrm{pH}$ was adjusted to 3.0, and it was analyzed according to the general procedure for extraction and determination of mercury content. 


\section{RESULTS AND DISCUSSION}

\section{Characterization of MNPs, ACMNPs and DTZ/SDS-ACMNPs}

It is most important that the ACMNPs as sorbent should possess suitable magnetic property. This property was studied by measuring the hysteresis and remanence curve by means of a vibrating sample magnetometer (VSM). The curve shows that ACMNPs with value of large saturation magnetization of $9.34 \mathrm{emu} \mathrm{g}^{-1}$ exhibit typical superparamagnetic behavior due to no hysteresis (Figure 2). Therefore, sorbent of ACMNPs is sufficient for magnetic separation with a conventional magnet.

A scanning electron microscope (SEM) was used to examine the surface of the MNPs and ACMNPs as adsorbent (Figure 3). The image of Figure 3b illustrates a highly porous morphology of adsorbent with uniform size distribution of the nanospheres.

The modified ACMNPs were confirmed by FT-IR analysis, as shown in Figure 4. In the spectrum of ACMNPs (Figure 4b), compared with the spectrum of MNPs, after binding alumina, and the broadening of the peak at $638.07 \mathrm{~cm}^{-1}$ can be assigned to $\mathrm{Al}-\mathrm{O}$, that overlapped with $\mathrm{Fe}-\mathrm{O}$ characteristic peak. ${ }^{47}$ Comparison of the FT-IR spectra of ACMNPs and DTZ/SDS-ACMNPs (Figure 4c) is also shows a new sharp peak at 1375.96 $\mathrm{cm}^{-1}$ appeared, it was due to that the $\mathrm{C}-\mathrm{N}$ stretching peak of DTZ stabilized on ACMNPs. Consequently, the FT-IR data suggest that DTZ are successfully immobilized on the ACMNPs surface.

\section{Amounts of SDS and DTZ}

Hiradie et al. proposed that water-insoluble chelating sorbents could be trapped into the aggregate of sodium dodecyl sulfate (SDS) on alumina particles. ${ }^{48}$ The molecules of anionic surfactants can effectively be sorbed on the positively charged surface. ACMNPs have positively charged surfaces in highly acidic solutions that can strongly adsorb a negatively charged surfactant such as

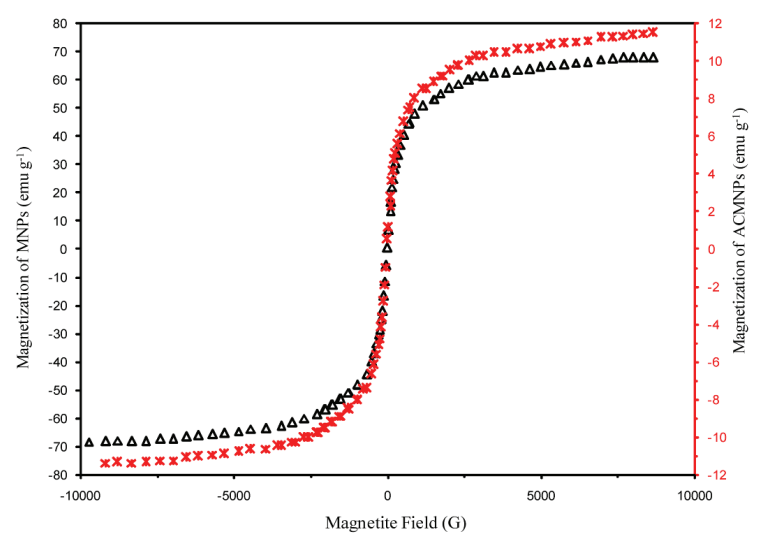

Figure 2. The magnetic behavior of MNPs $(\Delta)$ and ACMNPs $(*)$.

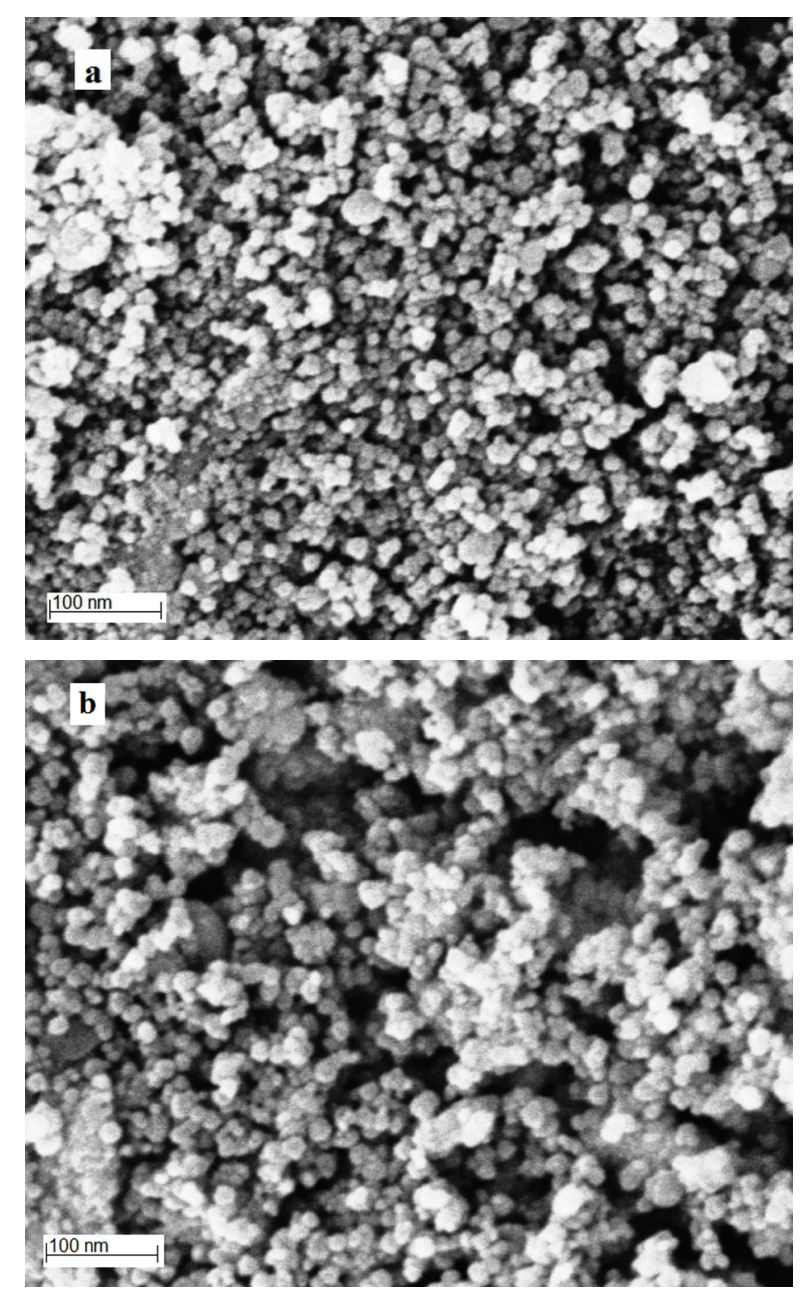

Figure 3. SEM images of MNPs (a) and ACMNPs (b).

SDS. A concentration of SDS, below its critical micellar concentration (CMC, $8 \mathrm{mmol} \mathrm{L}^{-1}$ ), was used. Above this concentration, the excess of SDS would form micelles in the aqueous solution, which were not adsorbed on alumina surfaces. Results show that with the increase of SDS concentration, the absorbance increases and a maximum is obtained after the SDS concentration approaches

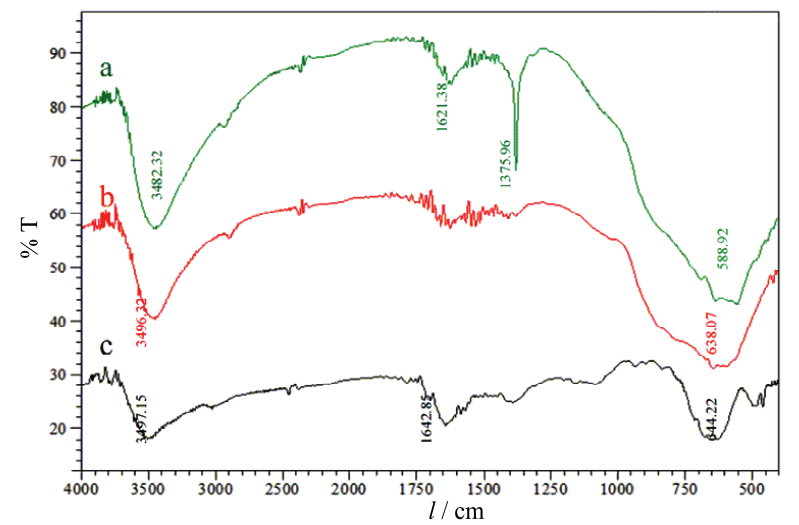

Figure 4. FTIR spectra of the MNPs (a), ACMNPs (b), and DTZ/SDS-ACMNPs (c). 
to $6.0 \times 10^{-2} \mathrm{mmol} \mathrm{L}^{-1}$ and remains constant up to $\mathrm{CMC}$ and then decreased, because above this point micelles are form strongly. Therefore, $0.1 \mathrm{mmol} \mathrm{L}^{-1} \mathrm{SDS}$ concentration was employed for further experiments.

In order to study the effect of DTZ concentration on adsorption of mercury ions on the ACMNPs, ammoniacal solutions of DTZ/SDS with constant concentration of SDS and different concentrations of DTZ were used. At DTZ concentrations less than $2.0 \times 10^{-2}$ mmol L $\mathrm{L}^{-1}$, the amount of DTZ molecules immobilized into SDS cores are too low to completely complex all mercury ions, so recoveries less than 100 were observed. At concentrations more than $2.0 \times 10^{-2} \mathrm{mmol} \mathrm{L}^{-1}$ of DTZ, the sorbent sites are too rich, with respect to DTZ molecules, to allow mercury ions to be adsorbed by formation of its DTZ complex. Therefore, $2.0 \times 10^{-2}$ mmol L ${ }^{-1}$ of DTZ was selected as the optimum concentration for further studies.

\section{Effect of pH}

The effect of $\mathrm{pH}$ was studied for the recovery of $10 \mathrm{~mL}$ mercury ion $\left(10 \mu \mathrm{g} \mathrm{mL}^{-1}\right)$ on $0.05 \mathrm{~g}$ of DTZ/SDS-ACMNPs (Figure 5). A series of $\mathrm{Hg}(\mathrm{II})$ solutions with different $\mathrm{pH}$ values from 2.0 to 12.0 were used, and the adsorbed mercury was eluted with $2 \mathrm{~mL}$ of $0.4 \mathrm{~mol} \mathrm{~L}^{-1}$ $\mathrm{HBr}$ solution. Results show that the adsorption behavior of metal ions was sensitive to $\mathrm{pH}$ changes. Proton in acid solution can protonate binding sites of the chelating molecules, and hydroxide in basic solution may complex and precipitate metal ions. ${ }^{49}$ Moreover, it is evident that the adsorption of mercury is quantitative $(>90 \%)$ at a $\mathrm{pH}$ range of $2.5-7.0$. Therefore, a $\mathrm{pH}$ of 3.5 was selected as the optimum $\mathrm{pH}$.

\section{Adsorption Isotherm}

The equilibrium isotherm of mercury ions adsorption by the SDS/DTZ-ACMNPs in acetate buffer solution at $\mathrm{pH}$ 3.5 and $25{ }^{\circ} \mathrm{C}$ is shown in Figure 6a. The adsorption behavior could be described by the Langmuir adsorption

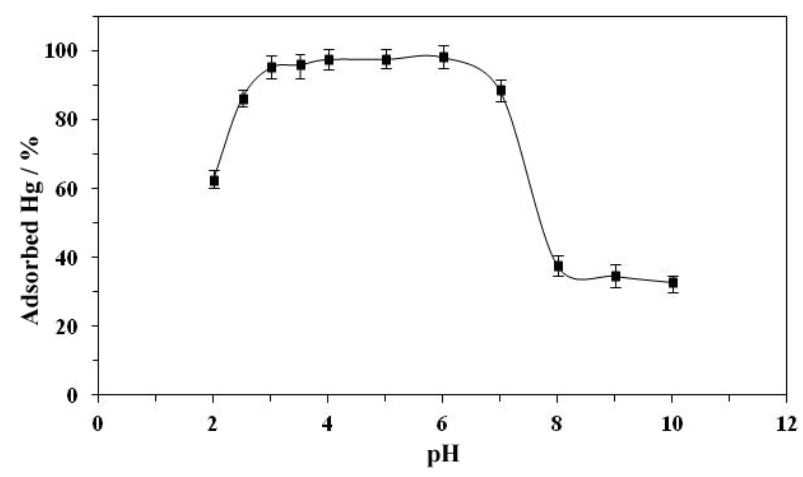

Figure 5. The effect of $\mathrm{pH}$ on the $\mathrm{Hg}(\mathrm{II})$ adsorption on SDS/DTZ-ACMNPs. Conditions: SDS/DTZ-ACMNPs (0.05 g), $\mathrm{Hg}$ (II) solution (10 mL, $10 \mu \mathrm{g} \mathrm{L}^{-1}$ ), temperature: $25^{\circ} \mathrm{C}$. equation:

$$
\frac{C}{Q}=\frac{1}{K q_{m}}+\frac{C}{q_{m}}
$$

where $Q$ is the equilibrium adsorption amount of $\mathrm{Hg}$ (II) $\left(\mathrm{mg} \mathrm{g}^{-1}\right), C$ is the equilibrium mercury ion concentration in the solution $\left(\mu \mathrm{g} \mathrm{L}^{-1}\right), q_{m}$ is the maximum adsorption amount of $\mathrm{Hg}$ (II) per gram of adsorbent $\left(\mathrm{mg} \mathrm{g}^{-1}\right)$ and $K$ is the Langmuir adsorption equilibrium constant $\left(\mathrm{mL} \mathrm{ng}^{-1}\right)$. A plot of $C / Q$ vs. $C$ yielded a straight line (Figure 6b). From the slope and intercept of the line, the values of $q_{m}$ and $K$ can be estimated to be $21.27 \mathrm{mg} \mathrm{g}^{-1}$ and $0.94 \mathrm{~mL} \mathrm{ng}^{-1}$, respectively.

\section{Standing and Magnetic Separation Time}

We found that the standing time had obvious effect on the SPE of target analyte. When the standing time were adjusted to 1, 3 and $5 \mathrm{~min}$, recoveries improved to 81 , 90 and $98 \%$; respectively. While, if the ACMNPs are isolated immediately without a standing process, the recovery of $\mathrm{Hg}(\mathrm{II})$ ions is only $40 \%$. Therefore, 5 min was sufficient to achieve satisfactory adsorption and better recovery of mercury ion. Meanwhile, in the
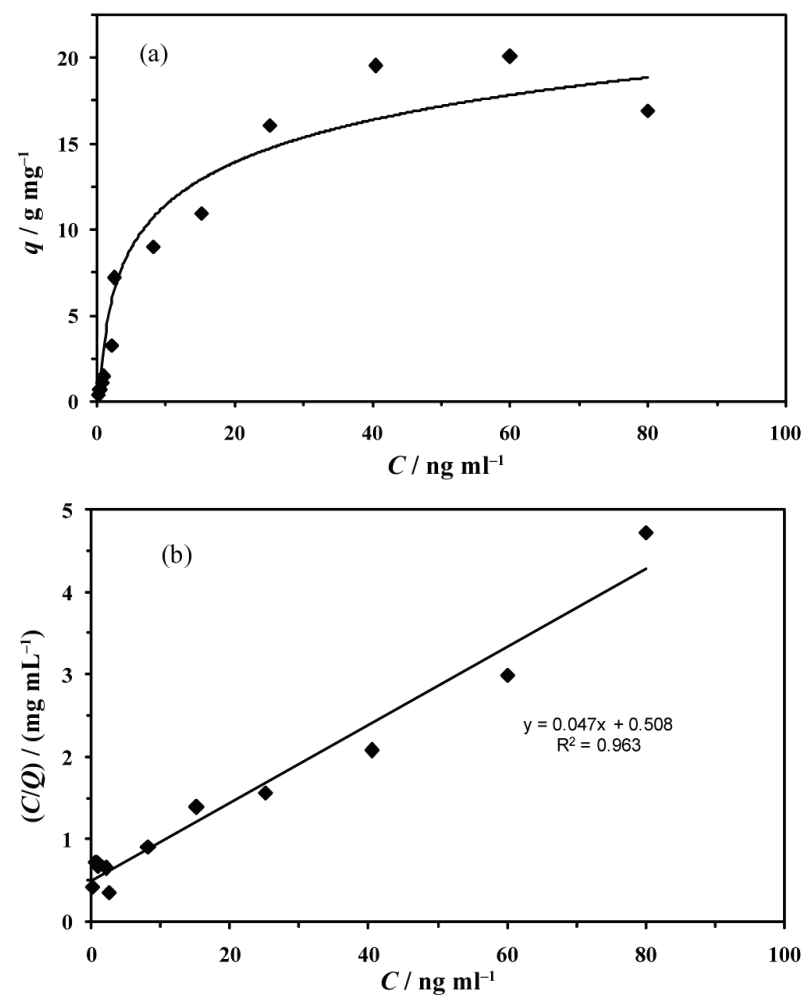

Figure 6. Adsorption isotherm of mercury on SDS/DTZACMNPs (a) Plot of $C / Q$ against $C$ for the adsorption of mercury on SDS/DTZ-ACMNPs. Conditions: ACMNPs (0.05 g), DTZ/SDS solution $\left(10 \mathrm{~mL}, 3 \times 10^{-2} \mathrm{mmol} \mathrm{L}^{-1} / 0.1 \mathrm{mmol} \mathrm{L}^{-1}\right.$, $\mathrm{pH}=3.0), \mathrm{Hg}(\mathrm{II})$ solution $\left(50 \mathrm{~mL}, 0.2-80 \mu \mathrm{g} \mathrm{mL}^{-1}\right)$; equilibrium time: $10 \mathrm{~h}$, temperature: $25^{\circ} \mathrm{C}$. 
experiment, DTZ/SDS-ACMNPs possessed superparamagnetism properties and large saturation magnetization, which enabled them to be completely isolated at the least time (less than $1 \mathrm{~min}$ ) by a strong magnet.

\section{Elution Condition, Maximum Sample Volume and Enrichment Factor}

A satisfactory eluent should effectively elute the sorbed analytes with small volume, which is needed for a high enrichment factor, and should not affect the accurate determination of the analytes and destroy life time and reusability of solid phase. Since the protonation of the amine groups under strong acid conditions, the coordination interaction of chelated $\mathrm{Hg}$ (II) ions could be easily disrupted and subsequently $\mathrm{Hg}$ (II) ions were released from loaded sorbents into desorption medium. So various concentrations $\left(0.1-1.0 \mathrm{~mol} \mathrm{~L} \mathrm{~L}^{-1}\right)$ and volumes $(0.5-10 \mathrm{~mL})$ of $\mathrm{HBr}, \mathrm{HNO}_{3}$ and $\mathrm{HCl}$ solutions were used for the desorption of retained $\mathrm{Hg}$ (II). The results show that maximum recoveries obtained in the optimum concentration of these solutions were 98.5, 84.7 and $87.0 \%$ for $\mathrm{HBr}, \mathrm{HNO}_{3}$ and $\mathrm{HCl}$, respectively. Results are shown, at a concentration more than $0.4 \mathrm{~mol} \mathrm{~L}^{-1}$ $\mathrm{HBr}$, mercury ions were completely desorbed from sorbent surfaces. Therefore, $2.0 \mathrm{~mL}$ of $0.4 \mathrm{~mol} \mathrm{~L}^{-1}$ are selected as the optimum volume and concentration of $\mathrm{HBr}$, respectively.

Due to low concentration of heavy metals, preconcentrations have been done on large volume of real samples. In order to explore the possibility of concentrating $\mathrm{Hg}$ (II) from low concentration of analytes in large volumes of solution and acquire a high enrichment factor, investigating the effects of sample volume on the retention of mercury ions is of great necessity. According to the proposed procedure, various volumes in the range of 50-1000 $\mathrm{mL}$ of sample solutions were tested (Figure 7) in which the total amount of $\mathrm{Hg}$ (II) ions was constant at $5.0 \mu \mathrm{g}$. The maximum sample volume can be up to $500 \mathrm{~mL}$ with the recovery $>95 \%$. The further increase of the sample volume led to significant decrease of the recovery. Therefore, $500 \mathrm{~mL}$ of the sample solution was adopted as the maximum sample volume for the preconcentration of $\mathrm{Hg}$ (II) from sample solutions. Thus, the higher enrichment factor was 250 since the final elution volume was $2.0 \mathrm{~mL}$.

\section{Effect of Co-existing Ions}

The optimal experimental conditions described above were used to study whether other co-existing ions that could act as interferents during the separation/preconcentration and analyte determination steps of the twostep method. The recovery of $10.0 \mu \mathrm{g} \mathrm{L} \mathrm{L}^{-1}$ of mercury ions was investigated in binary mixtures containing mercury ion and one of the foreign ions. The following excess of ions did not interfere the reaction (i.e., caused

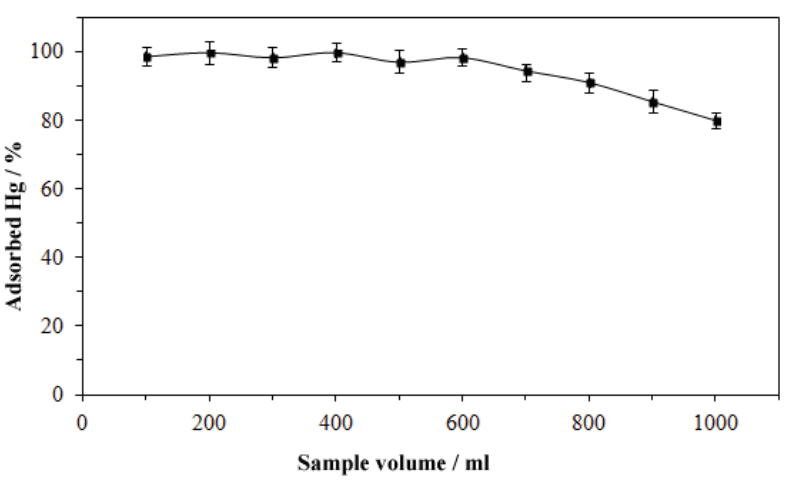

Figure 7. Effect of the sample volume on the recovery of $\mathrm{Hg}(\mathrm{II})$ from the SDS/DTZ-ACMNPs. Conditions: SDS/DTZACMNPs $(0.05 \mathrm{~g}), \mathrm{Hg}(\mathrm{II})$ solution $(0.1 \mu \mathrm{g}, \mathrm{pH}=3.5), \mathrm{HBr}$ as eluent solution $\left(0.4 \mathrm{~mol} \mathrm{~L}^{-1}\right)$, temperature: $25^{\circ} \mathrm{C}$.

a relative error of less than $5 \%$ ): more than a 10000 fold amount of $\mathrm{Na}^{+}, \mathrm{Ca}^{2+}, \mathrm{Mg}^{2+}$ and $\mathrm{K}^{+}$; a 1000 -fold amount of $\mathrm{Mn}^{2+}, \mathrm{Ni}^{2+}, \mathrm{Zn}^{2+}, \mathrm{Cu}^{2+}, \mathrm{Fe}^{2+}, \mathrm{Co}^{2+}, \mathrm{Cd}^{2+}, \mathrm{K}^{+}$, $\mathrm{Cr}^{3+}, \mathrm{Fe}^{3+}, \mathrm{Bi}^{3+}, \mathrm{Pd}^{2+}$ and $\mathrm{NH}_{4}^{+}$; a 500-fold amount of, $\mathrm{NO}_{3}{ }^{-}$and $\mathrm{CH}_{3} \mathrm{COO}^{-}$, a 200 -fold amount of $\mathrm{SO}_{4}{ }^{2-}, \mathrm{PO}_{4}{ }^{3-}$, $\mathrm{C}_{2} \mathrm{O}_{4}{ }^{2-}, \mathrm{Ag}^{+}, \mathrm{Pb}^{2+}$ and a 50 -fold amount of $\mathrm{I}^{-}, \mathrm{F}^{-}, \mathrm{Cl}^{-}$and $\mathrm{Br}^{-}$. The results showed that most of the investigated ions do not interfere in the adsorption-desorption and determination of traces of mercury ion in water samples.

\section{Reproducibility in Preparation of DTZ/SDS-ACMNPs and Sorbent Regeneration}

The reproducibility in preparation of DTZ/SDS-ACMNPs at same conditions for immobilized NPs that were produced different times was researched (constant in other conditions) and its effect at recovery was investigated and a relative standard deviation $(\mathrm{RSD})<6 \%$ observed in results.

Regeneration is one of the key factors for evaluating the performance of the sorbents. In this work, it was found that the ACMNPs can be reused up to five times without loss of analytical performance. This reusable number is suitable because $4.0 \mathrm{~g}$ of ACMNPs could be prepared in one batch and only $0.05 \mathrm{~g}$ of ACMNPs was used for one extraction operation.

\section{Analytical Performance and Method Validation}

In order to show the validation of the proposed method, under the optimal experimental conditions, the analytical features of the method such as limit of detection (LOD), linear range of the calibration curve and precision were examined. The LOD of the proposed method based on three times the standard deviation of the blank $\left(3 \mathrm{~S}_{\mathrm{b}}\right)$, was $0.058 \mu \mathrm{g} \mathrm{mL}^{-1}$ for mercury ion $(n=10)$. The linear range of calibration curve for $\mathrm{Hg}$ (II) was $0.2-80.0$ $\mathrm{ng} \mathrm{m}{ }^{-1}$ with a correlation coefficient of 0.9965 . The regression equation for the line was $A=0.093 C_{\mathrm{Hg}}+$ $\left(5.6 \times 10^{-3}\right)(n=5)$, where $C_{\mathrm{Hg}}$ is the concentration of 
Table 2. Recoveries results of real water samples spiked with mercury ions

\begin{tabular}{cccc}
\hline \multirow{2}{*}{ Sample } & \multicolumn{2}{c}{$\gamma(\mathrm{Hg}(\mathrm{II})) / \mu \mathrm{g} \mathrm{L}^{-1}$} & \multirow{2}{*}{ Recovery / \% } \\
\cline { 2 - 3 } & Added & Found & - \\
Tap water & 0 & - & 97.4 \\
(Sirjan) & 10 & $9.7( \pm 0.2)$ & 101.1 \\
& 20 & $20.2( \pm 0.4)$ & - \\
River water & 0 & - & 99.0 \\
(Hajiabad, & 10 & $9.9( \pm 0.3)$ & 102.5 \\
Bandar Abbas) & 20 & $20.4( \pm 0.3)$ & - \\
Spring water & 0 & - & 98.3 \\
(Koran, Sirjan) & 10 & $9.8( \pm 0.1)$ & 100.5 \\
\hline
\end{tabular}

Table 3. Mercury contents in various blood samples

\begin{tabular}{cccc}
\hline \multirow{2}{*}{ Sample } & \multicolumn{2}{c}{$\gamma(\mathrm{Hg}(\mathrm{II})) / \mu \mathrm{g} \mathrm{L}^{-1}$} & \multirow{2}{*}{ Recovery / \% } \\
\cline { 2 - 3 } & Added & Found & \\
\hline \multirow{2}{*}{1} & 0 & $3.4( \pm 0.4)$ & - \\
& 5 & $8.6( \pm 0.3)$ & 97.8 \\
2 & 0 & $7.5( \pm 0.6)$ & - \\
& 5 & $12.3( \pm 0.5)$ & 96.2 \\
\multirow{2}{*}{3} & 0 & $4.3( \pm 0.7)$ & - \\
& 5 & $9.4( \pm 0.2)$ & 102.4 \\
4 & 0 & $2.7( \pm 0.3)$ & - \\
& 5 & $8.0( \pm 0.4)$ & 106.4 \\
& 0 & $8.3( \pm 0.5)$ & - \\
& 5 & $12.2( \pm 0.6)$ & 98.4 \\
\hline
\end{tabular}

$\mathrm{Hg}(\mathrm{II})$ in $\mu \mathrm{g} \mathrm{mL}^{-1}$ and $A$ is the absorbance. The RSD for 10 replicate measurements of $5.0 \mu \mathrm{g} \mathrm{mL}^{-1}$ of mercury ion was $3.55 \%$.

\section{Analytical Applications}

In order to check the applicability of the proposed method it was applied to the seperation/preconcentration and determination of mercury in different samples of water and human's blood samples. The results tabulated in Tables 2 and 3. According this data, the added mercury ions can be quantitatively recovered from these samples by the proposed procedure. These results demonstrate, the presented procedure can be reliably applied for the separation/preconcentration and determination of $\mathrm{Hg}(\mathrm{II})$ in different samples of water and blood.

\section{CONCLUSION}

In this study, the new adsorbent (DTZ/SDS-ACMNPs) was prepared easily and low-costly utilized conveniently and harmless to environment. This sorbent was successfully applied for convenient, fast, simple and efficient enrichment of trace amounts of mercury ion from environmental water and blood samples. Magnetic separation in the method shortened analysis times greatly. The main benefits of this methodology are: no use of toxic organic solvent, simplicity and low cost. Furthermore, it avoids the time-consuming column passing (about $1 \mathrm{~h}$ in conventional SPE method) and filtration operation, and no clean-up steps were required. Table 4 shows a comparison of the proposed method with other reported SPE methods. It could be seen that some obtained values for

Table 4. Comparison of the proposed method with other reported methods for separation/preconcentration of mercury ions

\begin{tabular}{|c|c|c|c|c|c|c|}
\hline Adsorbent & $\begin{array}{l}\text { Detection } \\
\text { method }\end{array}$ & $\begin{array}{l}\text { Enrichment } \\
\text { factor }\end{array}$ & $\underset{\%}{\mathrm{RSD} /}$ & $\begin{array}{l}\text { Linear } \\
\text { range / } \\
\mu \mathrm{g} \mathrm{mL}^{-1}\end{array}$ & $\begin{array}{l}\text { Detection } \\
\text { limit / } \\
\mu \mathrm{g} \mathrm{mL}{ }^{-1}\end{array}$ & Ref. \\
\hline 2,6-Pyridine dicarboxylic acid/nanometer silica & ICP-AES & 175 & 3.0 & - & 0.09 & $(50)$ \\
\hline Dithizone/ neutral alumina & Spectrophotometry & 100 & 2.5 & - & 4.0 & $(51)$ \\
\hline 2-Mercaptobenzimidazole/agar & CV-AAS & 100 & 2.6 & $0.04-2.4$ & 0.02 & $(52)$ \\
\hline Dithizone/ neutral alumina & CV-AAS & 100 & 1.7 & $0.6-5.0$ & 0.11 & $(53)$ \\
\hline $\begin{array}{l}N \text {-(2-chlorobenzoyl)- } N \text {-phenylthiourea } \\
\text { loaded/sulfur }\end{array}$ & CV-AAS & 333 & 3.9 & $0.02-1.20$ & 0.012 & $(54)$ \\
\hline Dithizone/cellulose & Spectrophotometry & 33 & 3.5 & $0-2$ & 2.0 & $(55)$ \\
\hline Dithizone/silica gel & Spectrophotometry & 500 & 3.0 & $1.0-1500$ & 0.9 & $(56)$ \\
\hline \multirow{2}{*}{$\begin{array}{l}\text { 1,5-Bis(2-pyridyl)-3-sulphophenyl methylene } \\
\text { thiocarbonohydrazyde/Resin }\end{array}$} & CV-AAS & 28 & 3.4 & $0.1-30.0$ & 0.01 & \multirow{2}{*}{$(57)$} \\
\hline & CV-ETAAS ${ }^{(a)}$ & 42 & 3.5 & $0.009-1.5$ & 0.006 & \\
\hline $\begin{array}{c}\text { 1,4-Bis(4-pyridyl)-2,3-diaza-1,3-butadiene/ } \\
\text { Octadecyl silica cartridge }\end{array}$ & CV-AAS & 128 & 2.4 & $0.13-25.0$ & 0.05 & $(58)$ \\
\hline Dithizone/ACMNPs & CV-AAS & 250 & 3.55 & $0.2-80.0$ & 0.058 & This work \\
\hline
\end{tabular}

\footnotetext{
${ }^{(a)}$ Cold vapor-electrothermal atomic absorption spectrometry
} 
the proposed method such as linear range, LOD, sorbent capacity and enrichment factor are as or better than some of the previously reported methods. Moreover, total time of analysis of this method is reduced.

Acknowledgements. The authors would like to express their appreciations to Professor Afsaneh Safavi for her valuable discussion and useful suggestions. This research was supported by the Nanoscience and Nanotechnology Research Laboratory (NNRL) of Payame Noor University of Sirjan.

\section{REFERENCES}

1. D. M. Roundhill, J. Chem. Educ. 81 (2004) 275-282.

2. C. Baird, Environmental Chemistry, W. H. Freeman and Company, New York, 1999, p. 386.

3. U. Tamer, T. Oymak, and N. Ertas, Electroanalysis 19 (2007) 2565-2570.

4. X. Zhu and S. D. Alexandratos, Microchem. J. 86 (2007) 37-41.

5. L. Jian, W. Goessler, and K. J. Irgolic, Fresenius J. Anal. Chem. 366 (2000) 48-53.

6. K. Julshamn, A. Maage, H. S. Norli, K. H. Grobecker, C. A. L. Jorhem, and P. Fecher, J. AOAC Int. 90 (2007) 844-856.

7. Y. W. Chen, J. Tong, A. D'Uliv, and N. Belzile Analyst 127 (2002) 1541-1546.

8. N. V. Suc, M. M. Hung, and N. V. Hung, J. Radioanal. Nucl. Chem. 213 (1996) 65-70.

9. K. Julshamn and J. Brenna, J. AOAC Int. 85 (2002) 626-631.

10. R. W. Debeka, P. Bradley, and A. D. Mckenzie, J. AOAC Int. 85 (2002) 1136-1143

11. S. Gil, I. Lavilla, and C. Bendicho, Spectrochim. Acta Part B 62 (2007) 69-75.

12. V. Camel, Spectrochim. Acta Part B 58 (2003) 1177-1233.

13. D. E. Leyden, G. H. Luttrell, W. K. Nonidez, and D. B. Werho, Anal. Chem. 48 (1976) 67-70.

14. J. S. Jones, D. E. Harrington, B. A. Leone, and W. R. Bramdstedt, Atom. Spectrosc. 4 (1983) 49-54.

15. G. Seeber, P. Brunner, M. P. Bunchmeiser, and G. K. Bonn, J. Chromatogr. A 848 (1999) 193-202.

16. C. Caroli, A. Alimanti, F. Petrucci, and Z. Horvath, Anal. Chim. Acta 248 (1991) 241-249.

17. A. Alexandrova and S. Arpadjan, Analyst 118 (1993) 1309-1312.

18. G. Fang, J. Tan, and X. Yan, Anal. Chem. 77 (2005) 1734-1739.

19. E. M. Mohamed, Anal. Chim. Acta 398 (1999) 297-302.

20. H. Emteborg, D. C. Baxter, and W. Frech, Analyst 118 (1993) 1007-1013.

21. F. G. Matilde, P. G. Rosario, B. G. Nerea, and S. M. Alfredo, Talanta 41 (1994) 1833-1839.

22. H. A. M. Elamahadi and G. M. Greenway, J. Anal. Atom. Spectrom. 8 (1993) 1011-1116.

23. Y. Zhai, X. Chang, Y. Cui, N. Lia, and S. Lai, Microchim. Acta 154 (2006) 253-259.

24. E. M. Mohamed, M. O. Maher, and E. A. Mohamed, Anal. Chim. Acta 415 (2000) 33-40.

25. E. M. Mohamed and A. G. Gamal, Talanta 51 (2000) 77-87.

26. M. S. Ezzat, B. S. Mohamed, and A. A. Salwa, Anal. Chim. Acta 523 (2004) 133-140.

27. Q. He, X. Chang, X. Huang, and Z. Hu, Microchim. Acta $\mathbf{1 6 0}$ (2008) 147-152.
28. K. Hadjiivanov, K. Klissurski, M. Kantcheva, and A. Davydov, J. Chem. Soc. Faraday Trans 87 (1991) 907-911.

29. N. Lian, X. Chang, H. Zheng, S. Wang, Y. Cui, and Y. Zhai, Microchim. Acta 151 (2005) 81-88.

30. V. Bolis, B. Fubini, and E. Giamello, Mater. Chem. Phys. 29 (1991) 153-164

31. Y. Cui, X. Chang, Y. Zhai, X. Zhu, H. Zheng, and N. Lian, Microchem. J. 83 (2006) 35-41.

32. M. Tuzen and M. Soylak, B. Environ. Contam. Tox. 74 (2005) 968-972.

33. M. Tuzen, I. Karaman, D. Citak, and M. Soylak, Food Chem. Toxicolo. 47 (2009) 1648-1652.

34. M. Tuzen, I. Karaman, D. Citak, and M. Soylak, J. Hazard. Mater. 169 (2009) 345-350.

35. G. Cheng, M. He, H. Peng, and B. Hu, Talanta 88 (2012) $507-$ 515.

36. Y. Ji, X. Liu, M. Guan, C. Zhao, H. Huang, and H. Zhang, J. Sep. Sci. 32 (2009) 2139-2145.

37. H. Y. Tsai, C. F. Hsu, I. W. Chiu, and F. C. Bor, Anal. Chem. 79 (2007) 8416-8419.

38. J. Hu, G. Chen, and M. C. Irene, Water Res. 39 (2005) 4528 4536.

39. C. Huang and B. Hu, Spectrochim. Acta B 63 (2008) 437-444.

40. C. Huang and B. Hu, J. Sep. Sci. 31 (2008) 760-767.

41. S. Banerjee and D. Chen, J. Hazard. Mater. 147 (2007) 792-799.

42. A. Ngomsik, A. Bee, J. Siaugue, V. Cabuil, and G. Cote, Water Res. 40 (2006) 1848-1856.

43. M. Takafuji, S. Ide, H. Ihara, and Z. Xu, Chem. Mater. 16 (2004) 1977-1983.

44. M. A. Karimi, S. Z. Mohammadi, A. R. Mohadesi, A. HatefiMehrjardi, M. Mazloum-Ardakani, L. Sotudehnia Korani, and A. Askarpour Kabir, Scientia Iranica 18 (2011) 790-796.

45. M. A. Karimi, A. Hatefi-Mehrjardi, S. Z. Mohammadi, A. R. Mohadesi, M. Mazloum-Ardakani, M. R. Hormozi Nezhad, and A. Askarpour Kabir, J. Iran. Chem. Soc. 9 (2012) 171-180.

46. J. L. Manzoori, M. H. Sorouraddin, and F. Shemirani, Talanta 42 (1995) 1151-1155.

47. R. Y. Hong, J. H. Li, H. Z. Li, J. Ding, Y. Zheng and D. G. Wei, J. Magn. Magn. Mater. 320 (2008) 1605-1614.

48. M. Hiraide, M. H. Sorouraddin, and H. Kawaguchi, Anal. Sci. 10 (1994) 125-127.

49. L. J. Zhang, X. J. Chang, Y. H. Zhai, Q. He, X. P. Huang, Z. Hu, and N. Jiang, Anal. Chim. Acta 629 (2008) 84-91.

50. L. Zhang, X. Chang, Z. Hu, L. Zhang, J. Shi, and R. Gao, Microchim. Acta 168 (2010) 79-85.

51. N. Rajesh and G. Gurulakshmanan, Spectrochim. Acta A 69 (2008) 391-395.

52. N. Pourreza and K. Ghanemi, J. Hazard. Mater. 161 (2009) 982 987.

53. S. Dadfarnia, A. M. Salmanzadeh, and A. M. Haji Shabani, Bull. Korean Chem. Soc. 23 (2002) 1719-1723.

54. N. Pourreza, H. Parham, A. R. Kiasat, K. Ghanemi, and N. Abdollahi, Talanta 78 (2009) 1293-1297.

55. N. Rajesh and M. S. Hari, Spectrochim. Acta A 70 (2008) 1104 1108.

56. J. Fan, Y. Qin, C. Ye, P. Peng, and C. Wu, J. Hazard. Mater. 150 (2008) 343-350.

57. E. V. Alonso, M. T. Siles Cordero, A. García de Torres, P. Cañada Rudner, and J. M. Cano Pavón, Talanta 77 (2008) 53-59.

58. M. Soleimani, M. S. Mahmoudi, A. Morsali, A. Khani, and M. Ghahraman Afshar, J. Hazard. Mater. 189 (2011) 371-376. 